\title{
Thermoelectric Oxide Modules (TOMs) for the Direct Conversion of Simulated Solar Radiation into Electrical Energy
}

Petr Tomeš $^{1, *}$, Matthias Trottmann ${ }^{1}$, Clemens Suter ${ }^{2}$, Myriam Heidi Aguirre ${ }^{1}$, Aldo Steinfeld ${ }^{2,3}$, Philipp Haueter ${ }^{2}$ and Anke Weidenkaff ${ }^{1}$

1 Solid State Chemistry and Catalysis, EMPA, 8600 Duebendorf, Switzerland; E-Mails: matthias.trottmann@empa.ch (M.T); myriam.aguirre@empa.ch (M.H.A.); anke.weidenkaff@empa.ch (A.W.)

2 Department of Mechanical and Process Engineering, ETH Zurich, 8092 Zurich, Switzerland; E-Mail: suterc@ethz.ch (C.S.)

3 Solar Technology Laboratory, Paul Scherrer Institute, 5232 Villigen, Switzerland; E-Mail: aldo.steinfeld@ethz.ch (A.S.)

* Author to whom correspondence should be addressed; E-Mail: petr.tomes@empa.ch; Tel.: +41-44-823-4700; Fax: +41-44-823-4419.

Received: 8 January 2010; in revised form: 24 March 2010 / Accepted: 12 April 2010 / Published: 15 April 2010

Abstract: The direct conversion of concentrated high temperature solar heat into electrical energy was demonstrated with a series of four-leg thermoelectric oxide modules (TOM). These temperature stable modules were not yet optimized for high efficiency conversion, but served as proof-of-principle for high temperature conversion. They were constructed by connecting two $p$ - $\left(\mathrm{La}_{1.98} \mathrm{Sr}_{0.02} \mathrm{CuO}_{4}\right)$ and two $n$-type $\left(\mathrm{CaMn}_{0.98} \mathrm{Nb}_{0.02} \mathrm{O}_{3}\right)$ thermoelements electrically in series and thermally in parallel. The temperature gradient $\Delta T$ was applied by a High-Flux Solar Simulator source (HFSS) which generates a spectrum similar to solar radiation. The influence of the graphite layer coated on the hot side of the $\mathrm{Al}_{2} \mathrm{O}_{3}$ substrate compared to the uncoated surface on $\Delta T, P_{\max }$ and $\eta$ was studied in detail. The measurements show an almost linear temperature profile along the thermoelectric legs. The maximum output power of $88.8 \mathrm{~mW}$ was reached for a TOM with leg length of $5 \mathrm{~mm}$ at $\Delta \mathrm{T}=622 \mathrm{~K}$. The highest conversion efficiency $\eta$ was found for a heat flux of $4-8 \mathrm{~W} \mathrm{~cm}^{-2}$ and the dependence of $\eta$ on the leg length was investigated.

Keywords: thermoelectricity; thermoelectric converter; solar; heat transfer; radiation; modelling 


\section{Introduction}

The decrease of fossil fuel resources has motivated many research groups to seek technologies for the utilization of alternative energy sources [1,2]. Solar cells operating at $20 \%$ efficiency and covering $0.1 \%$ of the Earth's land area would be sufficient to supply the worldwide yearly required energy [3]. The Sun as energy source can also be used by thermoelectric (TE) modules which directly convert solar heat into electricity. The advantage of TE modules compared to photovoltaic (PV) solar cells is that TE modules utilize the whole solar spectrum (IR, UV and visible radiation), while PV cells only use the UV-Vis part of the spectrum [4].

The performance of a thermoelectric material is classified by the TE Figure of Merit, $Z T=S^{2} T / \rho \kappa$, where $S$ is the Seebeck coefficient, $\rho$ is the electrical resistivity and $\kappa$ is the thermal conductivity. In order to achieve a sufficient conversion efficiency $\eta$ at the given temperature, values of at least $Z T \sim 1$ are required. The maximum conversion efficiency is thermodynamically limited by the Carnot efficiency [5]. As was shown by Yang and Caillat [5], a Figure of Merit in the range of $2<\mathrm{ZT}<3$ results in conversion efficiencies of $\sim 50 \%$ of the Carnot efficiency. The real conversion efficiency depends not solely on the materials properties, but also on the construction and geometry of the TE device, as well as on the macroscopic heat and electronic transport.

Commercial thermoelectric devices are based on $\mathrm{Bi}_{2} \mathrm{Te}_{3}$ because this material exhibits a relatively high Figure of Merit [6,7]. Disadvantages of $\mathrm{Bi}_{2} \mathrm{Te}_{3}$ compounds are their limited chemical stability at high temperatures in air and their toxicity. Therefore, complex metal oxide ceramics as alternative materials are promising candidates for high temperature applications as they are inert at high temperatures in air, non-toxic, and low cost materials [8-12]. Among these oxides, $\mathrm{Na}_{\mathrm{x}} \mathrm{Co}_{2} \mathrm{O}_{4}$ is especially interesting as it shows a high Figure of Merit, ZT $\sim 0.8$ at $\mathrm{T}=800 \mathrm{~K}[13,14]$. The production of single crystals with defined and stable stoichiometry is difficult, though. In contrast, perovskite-type materials based on manganate and cuprate can be easily synthesized with controllable composition and TE properties.

In this paper we describe the direct conversion of solar heat into electrical energy by a series of perovskite-type thermoelectric oxide modules. The influence of the leg length, the emissivity of the absorber plate, the heat flux on the maximum output power $P_{\max }$ and the conversion efficiency $\eta$ is investigated to assess the potential of this technology.

\section{Experimental}

$P$-type $\mathrm{La}_{1.98} \mathrm{Sr}_{0.02} \mathrm{CuO}_{4}$ [15] and $n$-type $\mathrm{CaMn}_{0.98} \mathrm{Nb}_{0.02} \mathrm{O}_{3}$ [16] materials are used to build a series of four-leg thermoelectric oxide modules with leg lengths of 4, 5 and $10 \mathrm{~mm}$, respectively. The materials were prepared by a chimie douce synthesis procedure previously described [17]. The main advantage of this synthesis method, compared to the conventional solid state reaction method, is the homogeneity and purity of the product. The $p$ - and $n$-type powders were characterized by X-Ray Diffraction (XRD) $[15,16]$. The powders were pressed into disc-shaped pellets with a diameter of $20 \mathrm{~mm}$ using a hydrostatic press (up to $200 \mathrm{kPa}$ pressure). The $p$ - and $n$-type pellets were sintered for $16 \mathrm{~h}$ at $1,373 \mathrm{~K}$ and $1,523 \mathrm{~K}$, respectively.

The electrical resistivity and the Seebeck coefficient were measured with a RZ2001i Ozawa Science measurement system. The thermal conductivity was evaluated indirectly by separate 
measurements of the thermal diffusivity (Netzsch LFA apparatus) and the specific heat (Netzsch DSC apparatus). The electric and thermal transport properties were measured in the temperature range of $300 \mathrm{~K}<\mathrm{T}<800 \mathrm{~K}$. A detailed description of the TE measurements is reported in [18].

The four-leg thermoelectric oxide modules were assembled by connecting the $p$ - and $n$-type legs electrically in series and pressing them between two electrically insulated and thermally conductive $\mathrm{Al}_{2} \mathrm{O}_{3}$ layers [19]. A series of TOMs with different $A / l$ ratio ( $A$ is the cross-section area and $l$ is the leg length) were prepared. To Each leg had a surface area of $\sim 4.5 \times 4.5 \mathrm{~mm}^{2}$ to get an $A / l$ ratio which differs from $\sim 2 \mathrm{~mm}$ to $5 \mathrm{~mm}$. For validation of the experiment two of the TOMs with the same leg length were mounted and tested. The thermal contacts were provided by two $\mathrm{Al}_{2} \mathrm{O}_{3}$ substrates [19].The electrical contacts between the legs and the $\mathrm{Al}_{2} \mathrm{O}_{3}$ layers were made by brazing with a $0.1 \mathrm{~mm}$ thick $\mathrm{Ag}$ sheet by means of a conductor paste (DuPont). The TOMs were coated on the hot side by a homogeneous black graphite layer (Figure 1a) in order to increase the absorption of solar radiation by improving the emissivity $(\varepsilon)$. The $5 \mathrm{~mm}$ TOM 1 without coating as well as the $5 \mathrm{~mm}$ TOM 4 coated by $\mathrm{SiC}$ were measured for comparison. All the TOMs are summarized in Table 1.

Figure 1. (a) Sketch of a TOM testing unit mounted on the Al-holder for the thermocouples and glued on the $\mathrm{Cu}$-cooling part by means of thermal paste. The hot $\mathrm{Al}_{2} \mathrm{O}_{3}$ layer of the four - leg TOM is coated by a graphite layer. (b) Positions of the thermocouples in a cross-sectional profile of the $5 \mathrm{~mm}$ TOM. $0.5 \mathrm{~mm} \mathrm{~K}$-type thermocouples were placed in drilled holes.

(a)

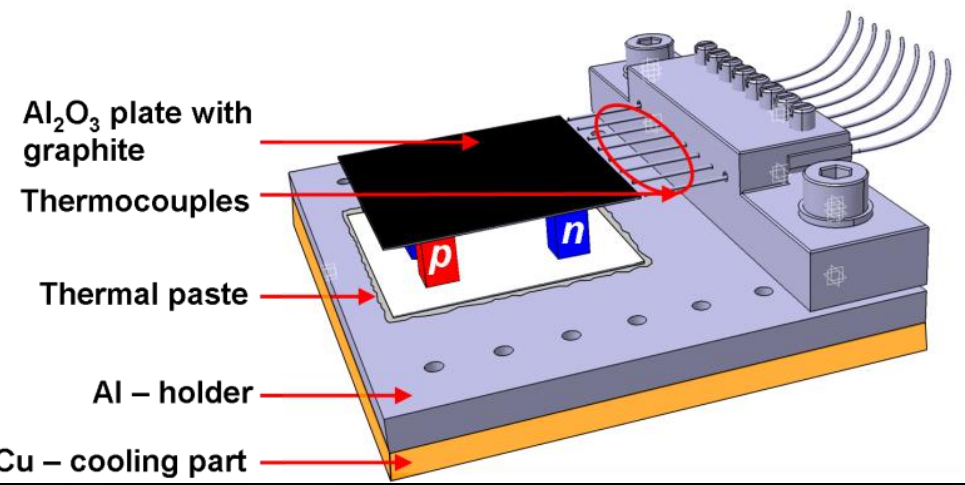

(b)

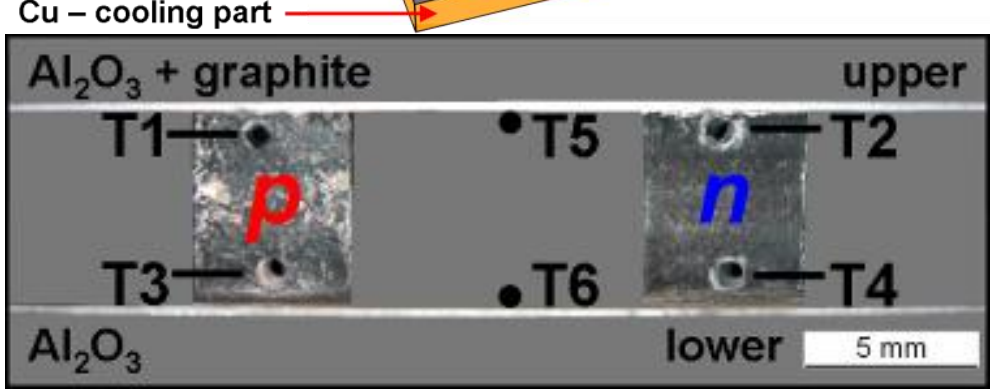

A HFSS was used as heat source (Figure 2) [20]. A water-cooled high-pressure argon arc lamp, enclosed in a quartz tube produces radiation in the visible, infrared and ultraviolet region. The power flux intensity and the temperature can be adjusted by varying the position of the target along the axis of the focusing mirrors or by changing the electrical input power at the arc electrodes. The HFSS is able to supply a flux intensity above $500 \mathrm{~W} \mathrm{~cm}^{-2}$ and to provide temperatures above $3000 \mathrm{~K}$. The input heat fluxes $\left(0-14.4 \mathrm{~W} \mathrm{~cm}^{-2}\right)$ were measured by a water cooled Thermogage Circular Foil Heat Flux 
Transducer TG1000-1 (Vatell Corporation) with a calibration range between $0-179 \mathrm{~W} \mathrm{~cm}^{-2}$, a sensor sensitivity of $0.084 \mathrm{mV} \mathrm{W}^{-1} \mathrm{~cm}^{-2}$ and a sensor emissivity of 0.97 .

The bottom side of the TOM was cooled by cold water circulating in a $\mathrm{Cu}$ block. TOMs were attached to the Al-holder using a thermally conductive paste (DuPont ${ }^{\mathrm{TM}}$ ) in order to increase the heat transfer from the cold $\mathrm{Al}_{2} \mathrm{O}_{3}$ layer to the $\mathrm{Al}$-holder. The $\mathrm{Al}$-holder itself was placed on the $\mathrm{Cu}$ block cooling unit with surface area of $50 \times 50 \mathrm{~mm}^{2}$ (Figure 1a).

A series of the $0.5 \mathrm{~mm}$ thick K-type thermocouples were used to measure the temperature on the hot and cold side of the TOM as well as in the $p$ - and $n$-type legs. One thermocouple was attached to the hot and cold $\mathrm{Al}_{2} \mathrm{O}_{3}$ absorber layer, respectively, and two to each TE leg by means of drilled holes with $0.6 \mathrm{~mm}$ in diameter (Figure $1 \mathrm{~b}$ ). The measurement accuracy of the temperature is limited by the thickness and position of the thermocouples. As the thickness of the thermocouple $d$ is $0.25 \mathrm{~mm}$, the measurement error of the temperature is: $\delta \mathrm{T}=\delta \mathrm{d}^{*}(\Delta \mathrm{T} / \Delta \mathrm{d})$.

Typical measurement started by applying different heat fluxes until the temperatures at the TOM showed steady state behavior. The man value temperatures were evaluated from the time dependence of temperatures for the given heat fluxes. The voltages in the open circuit mode, the load resistances and the temperatures on the hot and cold side of the TOMs and the $\mathrm{Al}_{2} \mathrm{O}_{3}$ substrates were recorded simultaneously.

A test unit with a data logger was used to measure the voltage in an open circuit mode and under load resistances. The test unit consisted of four resistances connected in parallel to yield 10 loads and a digital multimeter to measure the voltages. The measurements were monitored using the software LABVIEW. The output power was calculated from the voltage and load resistance values.

Figure 2. The High-Flux Solar Simulator at ETH: An elliptical mirror redirects the radiant power of the enclosed argon arc lamp onto the target (TOM).

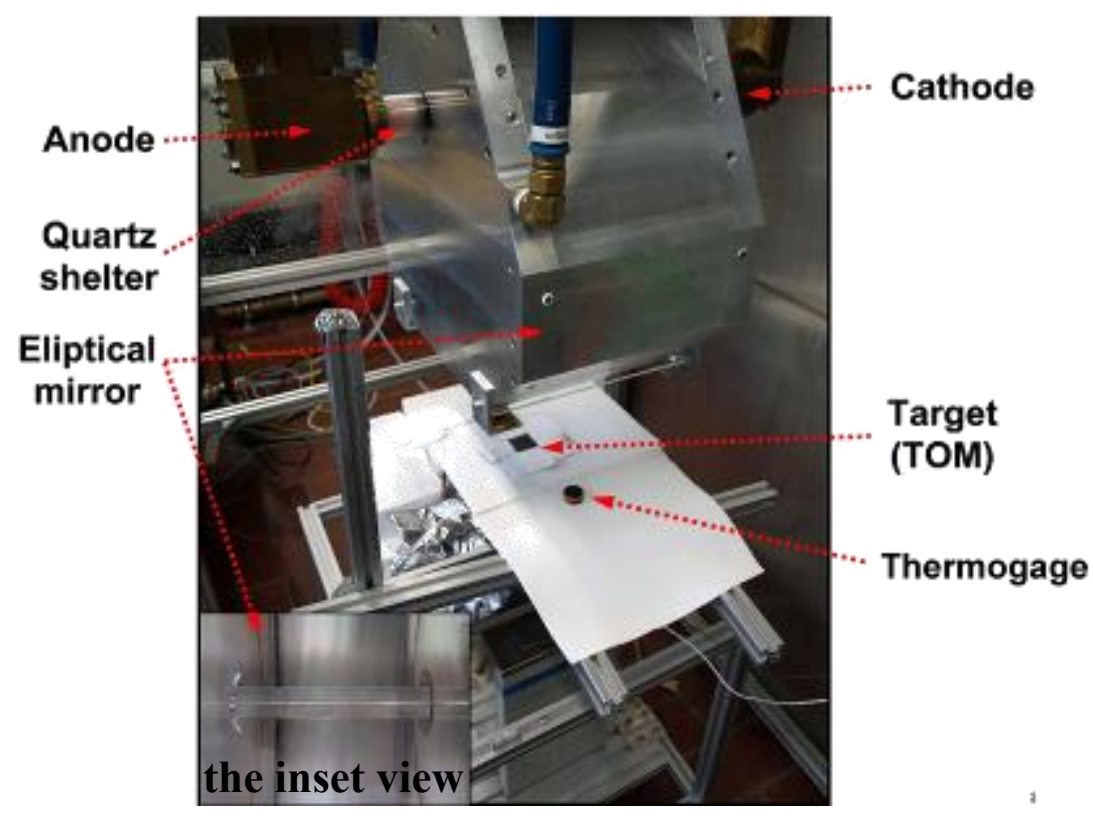




\section{Results and Discussion}

The $p$ - and $n$ - type TE materials were hydrostatically pressed into pellets. They showed $90 \%$ of the theoretical density without any crack formation due to the uniformly applied pressure. A high density of the TE legs is required in order to increase the electrical conductivity and to ensure a sufficient mechanical stability of the TE modules. The thermoelectrical properties of the materials are summarized in Figure 3. The $p$ - and $n$-type materials had thermal conductivities of $2.5 \mathrm{~W} \mathrm{~m}^{-1} \mathrm{~K}^{-1}$ and $3 \mathrm{~W} \mathrm{~m}^{-1} \mathrm{~K}^{-1}$ above $300 \mathrm{~K}$, respectively. Bocher et al. [21] measured a thermal conductivity $0.78 \mathrm{~W} \mathrm{~m}^{-1} \mathrm{~K}^{-1}$ lower above $300 \mathrm{~K}$ for the $n$-type material. The difference between the data can be attributed to modified synthesis conditions in order to obtain dense TE legs with good mechanical properties. A shorter sintering time and a lower sintering temperature $(\mathrm{T}=1,473 \mathrm{~K})$ resulted in samples with $80.77 \%$ of the theoretical density. In our case, the density exceeds $90 \%$ of the theoretical density. Further research on the relation between thermal conductivity and mechanical stability of the TE materials is needed.

Similar thermoelectric properties of the materials are a prerequisite for good conversion efficiencies of TE modules as was described previously by Snyder et al. [22]. The compatibility factor $s$, defined as:

$$
s=\frac{\left[(1+Z T)^{1 / 2}-1\right]}{S T}
$$

is used to assess the similarity of the TE properties of different material. For maximum conversion efficiencies of the thermoelectric modules at large temperature gradients, the compatibility factor should not vary much with temperature [22]. Both, the $p$ - and the $n$-type legs show similar metallic electrical resistivity values of $\rho_{p}=24 \mathrm{~m} \Omega \mathrm{cm}$ and $\rho_{n}=20 \mathrm{~m} \Omega \mathrm{cm}$ at T $=300 \mathrm{~K}$, respectively. Both materials exhibit a large thermopower $\left(S_{p}=+200 \mu \mathrm{V} \mathrm{K}^{-1}\right.$ and $\left.S_{n}=-160 \mu \mathrm{V} \mathrm{K}^{-1}\right)$ at T $=300 \mathrm{~K}$.

In Figure 3d, the open symbols show the temperature dependence of the Figure of Merit $Z T$ for the $p$ - and $n$-type material. In the temperature range of $300 \mathrm{~K}-450 \mathrm{~K}$ the $p$-type material has a higher $Z T$ than the $n$-type material due to its higher Seebeck coefficient. At $\mathrm{T}>400 \mathrm{~K}$ the $Z T$ of the $p$-type material decreases which is correlated to a decrease of the Seebeck coefficient $\left(S \sim 130 \mu \mathrm{V} \mathrm{K}^{-1}\right.$ at $800 \mathrm{~K}$ ) while the $Z T$ of the $n$-type material still increases due to $S \sim-240 \mu \mathrm{V} \mathrm{K} \mathrm{K}^{-1}$ in the same temperature region. The closed symbols in Figure $3 \mathrm{~d}$ show the temperature dependence of the compatibility factor $s$. The compatibility factors of both materials are perfectly matching around $\mathrm{T}=425 \mathrm{~K}$ but differ by a factor of 1.3 at $\mathrm{T}=500 \mathrm{~K}$ and by a factor of 2.3 at $\mathrm{T}=800 \mathrm{~K}$. This implies a decrease of the conversion efficiency of the four-leg modules at high temperature gradients.

The average temperature along the TOMs at different measurement positions depending on the heat flux are plotted in Figure 4a for 4, 5 and $10 \mathrm{~mm}$ leg length. At $\mathrm{T} \sim 910 \mathrm{~K}$ the graphite coating on the $\mathrm{Al}_{2} \mathrm{O}_{3}$ absorber plate starts to decompose which results in the decrease of the temperature difference between the hot and cold side of the module as well as in the decrease of the output power and conversion efficiency (cf. Figure 6). This is caused by the lower absorptivity of the $\mathrm{Al}_{2} \mathrm{O}_{3}$ absorber plate when the graphite layer is declining. With increasing heat flux, the temperature on the hot side of the module (T5) increases as expected. All measured results are summarized in Table I. 
Figure 3. Temperature dependence of (a) the thermal conductivity, (b) the electrical resistivity, (c) the Seebeck coefficient, (d) the Figure of Merit ZT and compatibility factor s of the $p$-type $\left(\mathrm{La}_{1.98} \mathrm{Sr}_{0.02} \mathrm{CuO}_{4}\right)$ and the $n$-type $\left(\mathrm{CaMn}_{0.98} \mathrm{Nb}_{0.02} \mathrm{O}_{3}\right)$ TE legs.
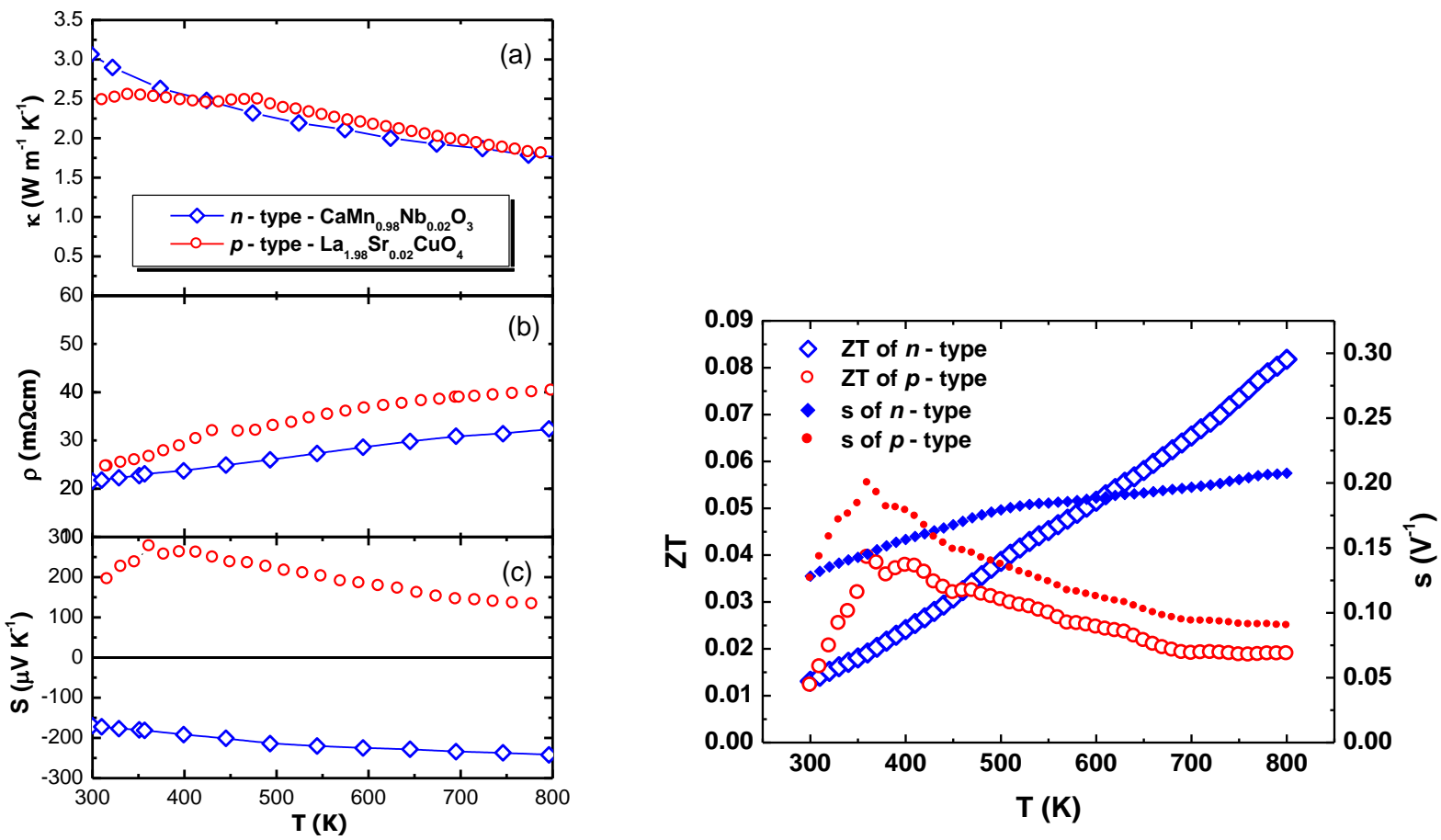

At the same heat flux, temperatures on the hot side of the $p$ - and $n$-type TE legs $(T 1, T 2)$, for the same TOM, are comparable which means the manufacturing quality of the interconnections between the hot $\mathrm{Al}_{2} \mathrm{O}_{3}$ layer and the $p$ - and $n$-type TE legs are rather reproducible and equivalent. Inducing absolute temperatures of $\mathrm{T}>400 \mathrm{~K}$, temperatures on the cold side of the module are lower in the $p$-type leg (T3) than the $n$-type leg (T4) at the same heat flux due to a higher thermal conductivity of the $p$-type material. At the cold $\mathrm{Al}_{2} \mathrm{O}_{3}$ plate (T6), temperatures are not alike which can be explained by an insufficient contact between the module and the Al-holder and deficiencies of the thermal paste. The difference is up to $\sim 140 \mathrm{~K}$ for the $4 \mathrm{~mm}$ TOM 1 and the $5 \mathrm{~mm}$ TOM 4 . The $5 \mathrm{~mm}$ TOM 4 was coated with $\mathrm{SiC}$ ( $\varepsilon \sim 0.7$; total spectrum measured) [23] so the lower temperature gradient compared to the graphite-coated $5 \mathrm{~mm}$ TOM 1 ( $\varepsilon \sim 0.95-0.97$; total spectrum measured) [23], was expectable (open blue circles in Figure 4a).

Figure $4 \mathrm{~b}$ shows the temperature profiles along the $p$ - and $n$-type legs. In the center of the $10 \mathrm{~mm}$ legs one additional $K$-type thermocouple was mounted (10 $\mathrm{mm}$ TOM 1$)$. The error on the $\mathrm{X}$-axis is estimated to be $\pm 0.25 \mathrm{~mm}$ which corresponds to an error of $\sim 6 \%$ of the absolute measured temperature value. The temperature gradient along the TE legs is almost linear. The $10 \mathrm{~mm}$ TOM 1 is showing lower temperatures in the $n$-type leg. This abnormality can be explained by the accuracy of the temperature measurement (position and embedding of the thermocouples) and/or a slightly larger cross-section of the $p$-type legs. 
Figure 4. (a) Temperatures in the module as a function of the heat flux for 4,5 and $10 \mathrm{~mm}$ TOMs. $5 \mathrm{~mm}$ TOM 4 was coated with $\mathrm{SiC}$ on the hot $\mathrm{Al}_{2} \mathrm{O}_{3}$ layer. (b) Temperature profiles along the $p$ - (red circle) and $n$-type (blue triangle) legs of the $4 \mathrm{~mm}, 5 \mathrm{~mm}$ and $10 \mathrm{~mm}$ TOMs.
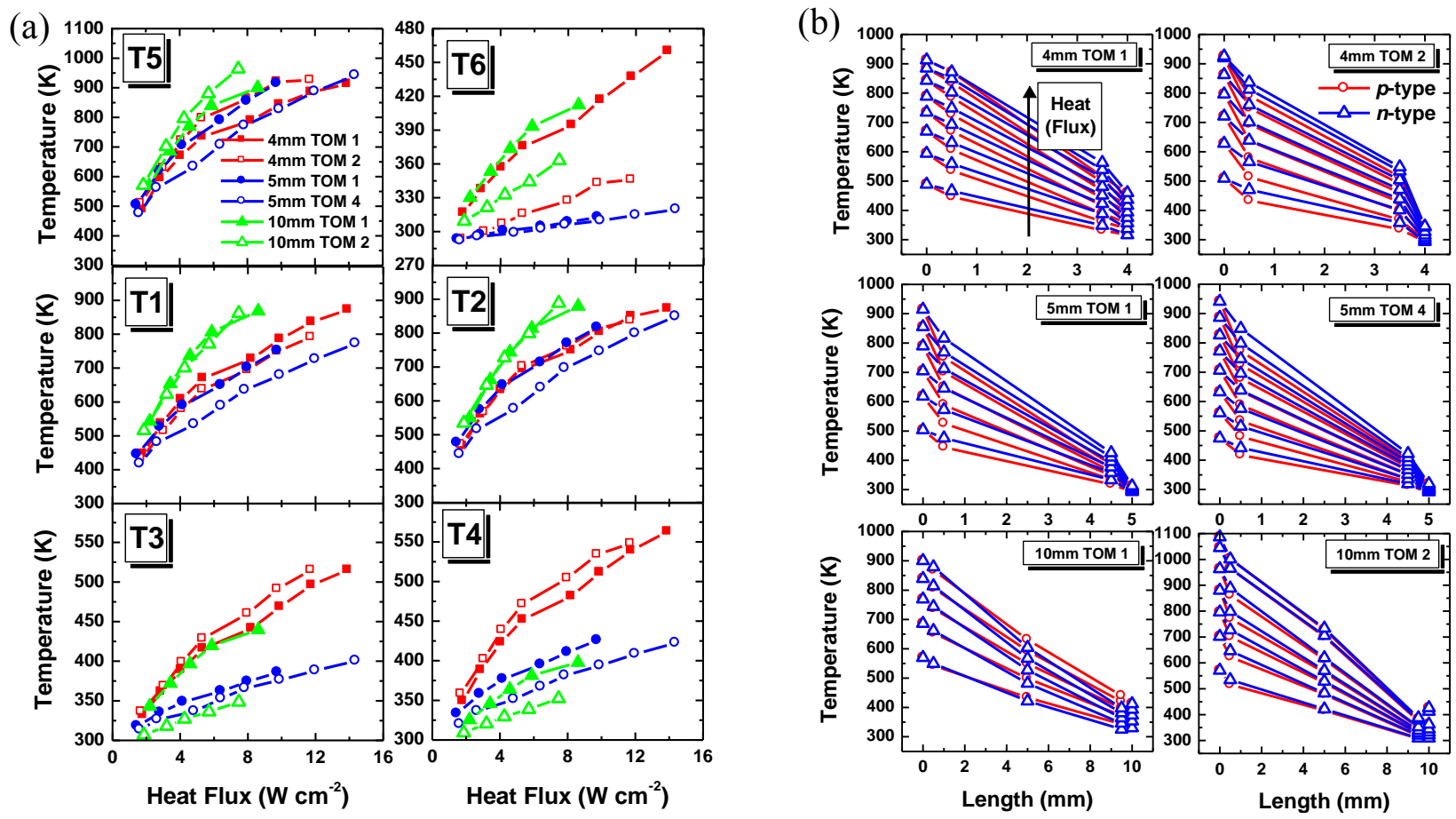

Table 1. Summary of the properties of four-leg TOMs.

\begin{tabular}{|c|c|c|c|c|c|c|c|c|c|c|}
\hline & $\begin{array}{c}\mathbf{T} 5_{\max } \\
{[\mathbf{K}]}\end{array}$ & $\begin{array}{c}6_{\max } \\
{[\mathrm{K}]} \\
\end{array}$ & $\begin{array}{l}\Delta \mathrm{T} \\
{[\mathrm{K}]} \\
\end{array}$ & $\begin{array}{c}\varepsilon \\
\text { [const.] }\end{array}$ & $\begin{array}{c}\mathbf{q}_{\text {in, } \max } \\
{\left[\mathbf{W} \mathbf{~ c m}^{-2}\right]}\end{array}$ & $\begin{array}{c}\mathbf{V}_{\text {OC, } \max } \\
{[\mathrm{mV}]}\end{array}$ & $\begin{array}{c}\eta \\
{[\%]}\end{array}$ & $\begin{array}{l}\mathbf{P}_{\max } \\
{[\mathrm{mW}]}\end{array}$ & $\begin{array}{c}\mathbf{q}_{\text {in, opt }} \\
{\left[\mathrm{W} \mathbf{c m}^{-2}\right]}\end{array}$ & $\begin{array}{l}\eta_{\max } \\
{[\%]}\end{array}$ \\
\hline $4 \mathrm{~mm}$ ТОМ 1 & 913 & 460 & 453 & $\sim 0.95$ & 13.90 & 42.9 & 0.043 & 53.7 & 4.06 & 0.065 \\
\hline $4 \mathrm{~mm}$ TOM 2 & 926 & 346 & 580 & $\sim 0.95$ & 11.72 & 39.4 & 0.044 & 46.1 & 5.33 & 0.060 \\
\hline 5 mm TOM 1 & 915 & 313 & 602 & $\sim 0.95$ & 9.75 & 44.5 & 0.059 & 51.6 & 7.98 & 0.060 \\
\hline $5 \mathrm{~mm}$ TOM 4 * & 941 & 319 & 622 & $\sim 0.70$ & 14.37 & 46.4 & 0.069 & 88.8 & 7.83 & 0.073 \\
\hline 10 mm TOM 1 & 901 & 412 & 489 & $\sim 0.95$ & 8.61 & 45.3 & 0.058 & 44.5 & 5.87 & 0.069 \\
\hline 10 mm ТОМ 2 & 964 & 363 & 601 & $\sim 0.95$ & 7.46 & 52.4 & 0.081 & 54.4 & 4.26 & 0.082 \\
\hline
\end{tabular}

$\Delta \mathrm{T}=\mathrm{T} 5_{\max }-\mathrm{T} 6_{\max } . \mathrm{T} 5_{\max }$ and $\mathrm{T} 6_{\max }$ are the maximum temperatures reached by applying maximum input heat flux $q_{\text {in, max }} ; V_{O C, \max }, \eta$ and $P_{\max }$ are the maximum open circuit voltage, efficiency and maximum output power reached by applying maximum input heat flux $\mathrm{q}_{\mathrm{in}, \max }$; $\mathrm{q}_{\mathrm{in} \text {, opt }}$ is the optimum input heat flux for reaching the maximum conversion efficiency $\eta_{\max } \cdot{ }^{*}$ Coated by SiC.

Figure 5a shows the influence of the absorber plate coating (graphite, SiC, non) on the absorptivity, the temperatures on the hot and cold $\mathrm{Al}_{2} \mathrm{O}_{3}$ plates, and on the temperatures in the $p$ - and $n$-type TE legs using the $5 \mathrm{~mm}$ TOM as example. The temperature difference on the hot $\mathrm{Al}_{2} \mathrm{O}_{3}$ absorber plate (T5) between the uncoated and the graphite-coated TOM is approximately $160 \mathrm{~K}$ at a heat flux of $9.5 \mathrm{~W} \mathrm{~cm}^{-2}$. On the one hand, the heat absorption is improved by changing the emissivity of the coated surface, but on the other hand insufficient cooling on the cold side of the module leads to an increase of T6 by $7 \mathrm{~K}$ at the same heat flux. 
Figure 5. (a) Temperatures as a function of the heat flux for a graphite-coated (black squares) and an uncoated (red circles) $5 \mathrm{~mm}$ TOM 1, compared with a SiC-coated (blue triangles) $5 \mathrm{~mm}$ TOM. (b) Maximum output power and (c) conversion efficiency as function of the heat flux of a $5 \mathrm{~mm}$ TOM 1 and $5 \mathrm{~mm}$ TOM 4.

(a)

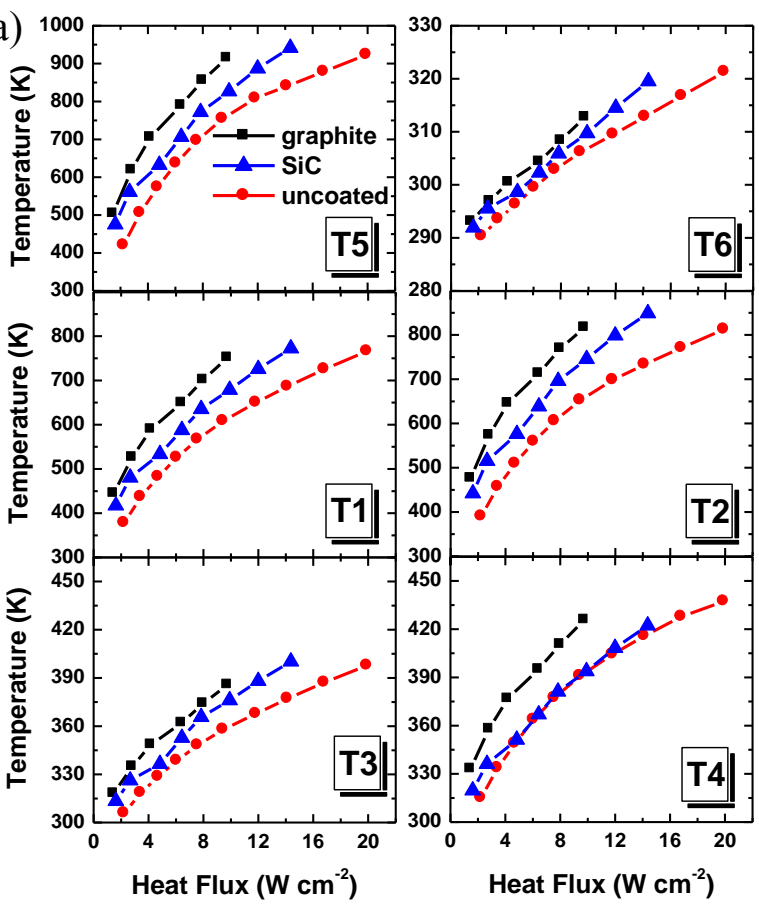

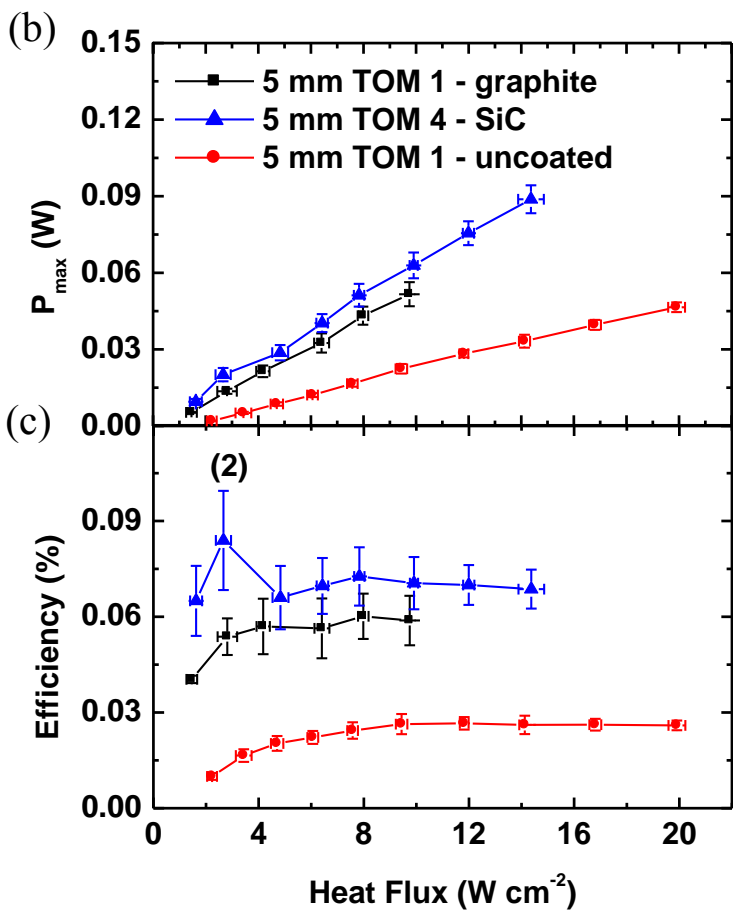

Based on the voltage measurement in open circuit mode $\left(V_{o c}\right)$ and at load resistances, the maximum output power $\left(P_{\max }\right)$ was calculated considering the load resistance equal to the internal resistance [19]. $P_{\max }$ is plotted in Figure 5b. As expected it was found that $P_{\max }$ is higher for the graphite-coated than for the uncoated module. At the same heat flux of $\sim 9.5 \mathrm{~W} \mathrm{~cm}^{-2}$, the temperature difference between $T 5$ and $T 6$ is $602 \mathrm{~K}$ and $448 \mathrm{~K}$ for the graphite-coated and the uncoated $5 \mathrm{~mm}$ TOM, respectively. Accordingly, an open circuit voltage $V_{O C}$ of $44.6 \mathrm{mV}$ (graphite-coated) and $31.7 \mathrm{mV}$ (uncoated) was measured which results in values for $P_{\max }$ of $51.6 \mathrm{~mW}$ and $22.6 \mathrm{~mW}$ for the graphite-coated and uncoated $5 \mathrm{~mm}$ TOM, respectively. For the $5 \mathrm{~mm}$ SiC-coated TOM 4, $V_{O C}=38.3 \mathrm{mV}$, $T 5-T 6=507 \mathrm{~K}$ and $P_{\max }=60.6 \mathrm{~mW}$ at a heat flux of $\sim 9.5 \mathrm{~W} \mathrm{~cm}^{-2}$ was determined. Despite the lower emissivity of $\mathrm{SiC}(\varepsilon=0.7)$ compared to graphite $(\varepsilon \sim 0.95)$ the $5 \mathrm{~mm}$ TOM 4 has a higher maximum output power $P_{\max }$ even though the open circuit-voltage $V_{O C}$ is smaller. As the same $p$ - and $n$-type materials are used for all the TOMs, this finding might be explained by small manufacturing deviations which could affect the contact resistances $R_{\text {cont }}$.

Knowing the input heat flux measured by the Thermogage and the open-circuit voltage $V_{o c}$ measured by a test unit with a data logger, we can calculate the conversion efficiency $\eta$, defined by:

$$
\eta=\frac{V_{O C}^{2}}{4 R_{\text {load }}\left(\frac{V_{O C}-V_{\text {load }}}{V_{\text {load }}}\right) Q_{\text {in }}},
$$


where $V_{\text {load }}$ is the voltage at load resistance, $R_{\text {load }}$ is the load resistance, and $Q_{\text {in }}$ is the solar power input in [W] on the surface of the $\mathrm{Al}_{2} \mathrm{O}_{3}$ absorber plate. Conversion efficiencies against heat flux for the 5 $\mathrm{mm}$ TOMs are presented in Figure 5c. The conversion efficiencies of the graphite-coated $5 \mathrm{~mm}$ TOM 1 and the SiC-coated $5 \mathrm{~mm}$ TOM 4 are higher than the efficiency of the uncoated $5 \mathrm{~mm}$ TOM 1 which is in agreement with the $P_{\max }$ results. As for the $5 \mathrm{~mm}$ TOM 4, the fluctuation of $\eta\left(2^{\text {nd }}\right.$ point of the blue curve in Figure 5c) was caused by a combination of the radiation fluctuation (horizontal error bars) and the instability of $V_{\text {load }}$ (vertical error bars).

Figure 6a-d summarize the data of $P_{\max }$ and $\eta v s$. heat flux and T5 - T6 for 4, 5 and $10 \mathrm{~mm}$ TOMs coated by graphite $(5 \mathrm{~mm}$ TOM 4 coated by $\mathrm{SiC}$ ). Depending on the temperature difference $T 5-T 6$ the maximum output power $P_{\max }$ increases as $P_{\max } \sim f\left(\Delta T^{2}\right)$ and a maximum value of $54.4 \mathrm{~mW}$ was achieved for a leg length of $10 \mathrm{~mm}$ at a heat flux of $9.5 \mathrm{~W} \mathrm{~cm}^{-2}\left(5^{\text {th }}\right.$ point in Figure $\left.6 \mathrm{a}\right)$. A maximum output power of $88.8 \mathrm{~mW}$ was obtained for the $5 \mathrm{~mm}$ TOM 4 at a heat flux of $14.4 \mathrm{~W} \mathrm{~cm}^{-2}$ and a temperature difference of $T 5-T 6=622 \mathrm{~K}$. A conversion efficiency of $0.082 \%$ was obtained for a TOM with $10 \mathrm{~mm}$ leg length and an $\mathrm{Al}_{2} \mathrm{O}_{3}$ absorber area of $30 \times 30 \mathrm{~mm}^{2}$ (Figures $6 \mathrm{~b}, \mathrm{~d}$ ). As expected longer TE legs lead to higher conversion efficiency [24].

The conversion efficiency is higher at higher heat fluxes resulting in higher temperature differences T5 - T6 which improves the Carnot efficiency. The conversion efficiency reaches the maximum for $4 \mathrm{~mm}$ TOMs around $4 \mathrm{~W} \mathrm{~cm}^{-2}$, for $5 \mathrm{~mm}$ TOMs between 4-8 $\mathrm{W} \mathrm{cm}^{-2}$ and for $10 \mathrm{~mm}$ TOMs around 6 $\mathrm{W} \mathrm{cm} \mathrm{cm}^{-2}$. After reaching the maximum value, the conversion efficiency decreases because of a degradation of the graphite at high temperatures when the heat flux exceeds $7.5 \mathrm{~W} \mathrm{~cm}^{-2}$. A further reason for decrease of the conversion efficiency are the re-radiation losses from the $\mathrm{Al}_{2} \mathrm{O}_{3}$ absorber plate. The re-radiation losses from the $\mathrm{Al}_{2} \mathrm{O}_{3}$ absorber plate increase with $T^{4}$.

As the radiation losses are difficult to measure directly, a simulation procedure was developed [25]. The results show that there is no significant radiation between the $\mathrm{Al}_{2} \mathrm{O}_{3}$ absorber plates and the TE legs, but the major heat losses of $\sim 60 \%$ are due to the re-radiation from the hot side of the $\mathrm{Al}_{2} \mathrm{O}_{3}$ absorber plate.

In an ideal case the internal resistance $R_{\text {int }}$ of the module is equal to the resistance of the thermoelectric oxide material $R_{\text {mater }}$. However, in real thermoelectric modules, the effect of the contact resistance on the conversion is not negligible. It is well known that high contact resistances lower the conversion efficiency of the devices remarkably. The internal resistances, contact resistances and resistances of the material for the TOMs were evaluated for the highest applied $\Delta \mathrm{T}$ based on the following equations:

$$
\begin{gathered}
R_{\mathrm{int}}=R_{\text {mater }}+R_{\text {cont }}, \text { where } R_{\text {mater }}=2 \frac{l}{A} \int_{T 6}^{T 5}\left(<\rho_{p}>+<\rho_{n}>\right)\left(T_{5}-T_{6}\right) \\
R_{\mathrm{int}}=\frac{V_{O C}^{2}}{4 P_{\text {max }}} \text { when } R_{\text {load }}=R_{\mathrm{int}} .
\end{gathered}
$$


Figure 6. Maximum output power and conversion efficiency of the TOMs as a function of the heat flux $(a, b)$ and the temperature difference between the hot and the cold plate $(c, d)$.

(a)

(b)

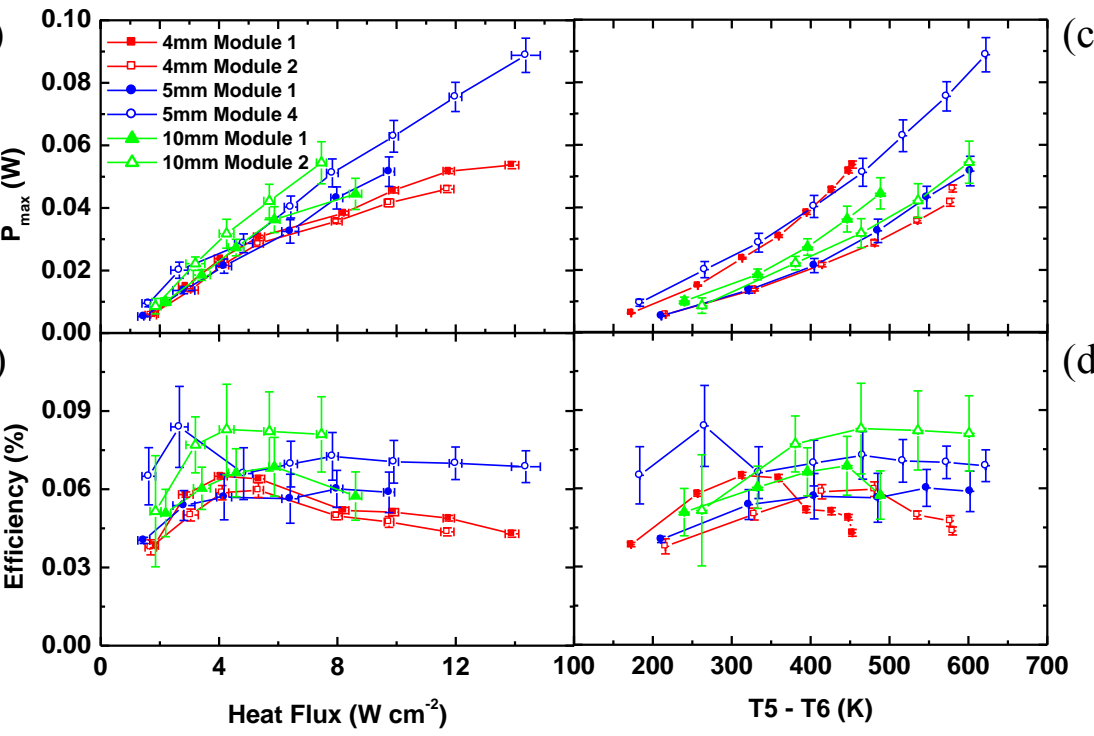

(c)

(d)

The results are summarized in Table 2 as well as the other relevant physical parameters, such as average values of Seebeck coefficient and electrical resistivity of $p$-and $n$-type TE legs for all TOMs. The internal resistance increases with leg length because of the increase of the $R_{\text {mater }}$. The contact resistance vary in the range of $0.29 \Omega<R_{\text {cont }}<0.64 \Omega$ depending on the manufacturing quality of TOMs.

Table 2. Physical parameters of four-leg TOMs.

\begin{tabular}{|c|c|c|c|c|c|c|c|c|c|c|c|}
\hline & $\begin{array}{l}\Delta \mathrm{T} \\
{[\mathrm{K}]} \\
\end{array}$ & $\begin{array}{c}\mathbf{A} / \mathbf{l} \\
{[\mathrm{mm}]}\end{array}$ & $\begin{array}{c}<S_{p_{p}}> \\
{\left[\mu V K^{-1}\right]}\end{array}$ & $\begin{array}{c}<S_{n}> \\
{\left[\mu V K^{-1}\right]}\end{array}$ & $\begin{array}{c}<\boldsymbol{\rho}_{\mathrm{p}}> \\
{[\mathrm{m} \boldsymbol{\Omega} \mathbf{~ c m}]}\end{array}$ & $\begin{array}{c}<\rho_{\mathrm{n}}> \\
{[\mathrm{m} \Omega \mathrm{cm}]}\end{array}$ & $\begin{array}{l}\mathbf{R}_{\text {int }} \\
{[\Omega]}\end{array}$ & $\begin{array}{c}\mathbf{R}_{\text {mater }} \\
{[\Omega]}\end{array}$ & $\begin{array}{c}\mathbf{R}_{\text {cont }} \\
{[\Omega]}\end{array}$ & $\begin{array}{c}\text { MQF1 } \\
{[\%]}\end{array}$ & $\begin{array}{c}\text { MQF2 } \\
{[\%]} \\
\end{array}$ \\
\hline $4 \mathrm{~mm}$ TOM 1 & 453 & 5.06 & 162.0 & -230.8 & 37.8 & 30.0 & 0.86 & 0.27 & 0.59 & 23 & 31 \\
\hline $4 \mathrm{~mm}$ TOM 2 & 580 & 5.06 & 179.3 & -223.5 & 36.3 & 28.9 & 0.84 & 0.26 & 0.58 & 11 & 31 \\
\hline $5 \mathrm{~mm}$ TOM 1 & 602 & 4.05 & 182.6 & -220.4 & 35.6 & 28.5 & 0.96 & 0.32 & 0.64 & 14 & 33 \\
\hline $5 \mathrm{~mm}$ TOM 4 & 622 & 4.05 & 179.8 & -221.9 & 35.9 & 28.7 & 0.61 & 0.32 & 0.29 & 23 & 52 \\
\hline $10 \mathrm{~mm}$ TOM 1 & 489 & 2.03 & 171.3 & -227.4 & 37.1 & 29.4 & 1.15 & 0.66 & 0.49 & 38 & 57 \\
\hline $10 \mathrm{~mm}$ TOM 2 & 601 & 2.03 & 173.2 & -226.1 & 37.0 & 29.0 & 1.26 & 0.65 & 0.61 & 31 & 52 \\
\hline
\end{tabular}

$\left.<\mathrm{S}_{\mathrm{p}}\right\rangle,\left\langle\mathrm{S}_{\mathrm{n}}\right\rangle,\left\langle\rho_{\mathrm{p}}\right\rangle$ and $\left\langle\rho_{\mathrm{n}}\right\rangle$ is the average Seebeck coefficient for $p$-type, $n$-type leg and average electrical resistivity for $p$-type, $n$-type leg, respectively.

The more detailed determination of the contact resistance was done by measurement of $5 \mathrm{~mm}$ $n$-type TE leg at several temperature differences which vary from $0 \mathrm{~K}$ to $410 \mathrm{~K}$. The measurement configuration is shown in Figure 7a. From the evaluation of $\left\langle\rho_{\mathrm{n}}\right\rangle$ and the internal resistance $R_{\text {int }}$ measurement, the contact resistance on the hot side $R_{\text {conthot }}$ and the cold side $R_{\text {contcold }}$ of the $5 \mathrm{~mm}$ $n$-type leg was determined. The evaluation of $R_{\text {conthot }}, R_{\text {contcold }}$ and $R_{\text {int }}$ was done based on the following equations: 


$$
\begin{gathered}
R_{\mathrm{int}}=\int_{T_{6}}^{T_{5}} R_{\text {mater }} \frac{d\left(T_{5}-T_{6}\right)}{T_{5}-T_{6}}+R_{\text {contcold }}+R_{\text {conthot }} \\
R_{x y}=\int_{T_{6+Z}}^{T_{5}} R_{\text {mater } Y} \frac{d\left(T_{5}-T_{6+Z}\right)}{T_{5}-T_{6+Z}}+R_{\text {conthot }} \\
R_{y z}=\int_{T_{6+Y+Z}}^{T_{5}} R_{\text {mater }, X} \frac{d\left(T_{5}-T_{6+Y+Z}\right)}{T_{5}-T_{6+Y+Z}}+R_{\text {contcold }} .
\end{gathered}
$$

The data of the contact resistance measurement were normalized and plotted in Figure $7 \mathrm{~b}$. It was shown, that the major contribution to internal resistance is the contact resistance on the cold side and the hot side of the TOM compared to the resistance of the thermoelectric oxide materials. Thus, it can be concluded that for better conversion experiments the contacts have to be improved to decrease the contact resistance of the TOMs by e.g. developing better contact materials.

Figure 7. Contact resistance measurement configuration based on Equations 5-7 (a) and normalized $R_{\text {int }}, R_{\text {mater }}, R_{\text {contcold }}$ and $R_{\text {conthot }}$ for $5 \mathrm{~mm} n$-type TE leg (b).

(a)
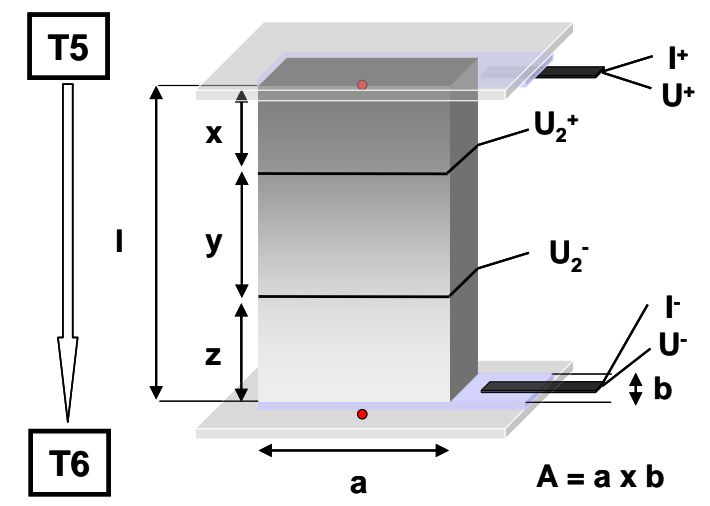

$\mathrm{Al}_{2} \mathrm{O}_{3}$ substrate

Ag electrical contact

Ag electrode

- K-type thermocouple (b)

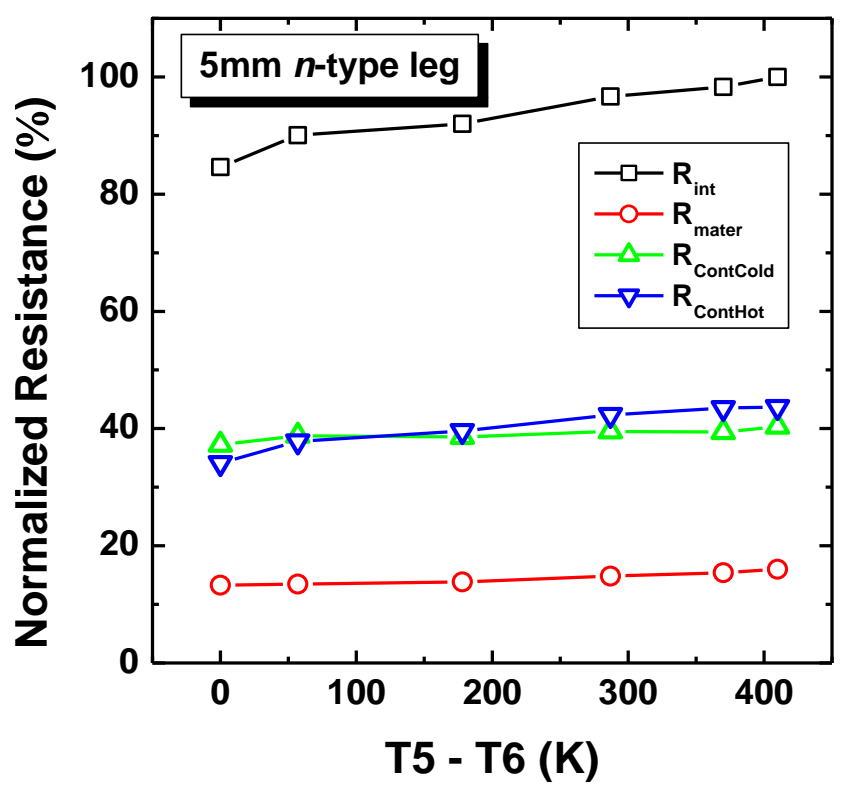

Quantitative measures of the device quality are the manufacture quality factors $M Q F 1$, and $M Q F 2$ $[24,26]$. These factors were calculated to determine the eventual ambiguity associated with the manufacturing defects of TOMs based on the following equations:

$$
\begin{gathered}
M Q F 1=\frac{P_{\max }}{N \Delta T^{2}\left(S^{2} / 2 \rho\right)(A / l)}, \\
M Q F 2=\frac{R_{\text {mater }}}{R_{\text {int }}}
\end{gathered}
$$


where $N$ is the number of thermocouples in a TOM, $\Delta T$ is the temperature gradient between the hot side and the cold side of the TOM, $S$ is the Seebeck coefficient, $\rho$ is the electrical resistivity, $A$ is the cross-sectional area of TE leg and $l$ is the leg length. The manufacture quality factors vary in the range of $11 \%<M Q F 1<38 \%$ and $31 \%<M Q F 1<57 \%$, respectively. The manufacture quality factor values calculated by using Equation 9 were comparable with previous studies on thermoelectric oxide modules [26]. In the case of the $5 \mathrm{~mm}$ TOM 1 with $P_{\max }=51.6 \mathrm{~mW}$ and $5 \mathrm{~mm} \mathrm{TOM} 4$ with $P_{\max }=$ $88.8 \mathrm{~mW}$ it was evident that the maximum output power was enhanced by lowering the contact resistance. The manufactory quality factor measured under a similar temperature gradients of the $5 \mathrm{~mm}$ TOM 4 was $M Q F 2=52 \%$ while the $5 \mathrm{~mm}$ TOM 1 revealed a different MQF of $M Q F 2=33 \%$.

\section{Conclusions}

Four-leg thermoelectric oxide modules, combining $p$ - and $n$-type thermoelements made of $\mathrm{La}_{1.98} \mathrm{Sr}_{0.02} \mathrm{CuO}_{4}$ and $\mathrm{CaMn}_{0.98} \mathrm{Nb}_{0.02} \mathrm{O}_{3}$, respectively, were successfully used to directly convert simulated solar radiation into electrical energy by using a HFSS as energy source. The Figure of Merit ZT of the $p$ - and $n$-type thermoelectric materials was evaluated up to $800 \mathrm{~K}$ showing nearly constant values at higher temperatures for the $p$-type and a linear increase with temperature up to ZT $=0.08$ for the $n$-type material. The electrical resistivity of both materials shows metallic behavior with $\rho$ between $20-24 \mathrm{~m} \Omega \mathrm{cm}$ at and $|\mathrm{S}| \geq 160 \mu \mathrm{V} \mathrm{K}^{-1}$ at $\mathrm{T}=300 \mathrm{~K}$. The temperature gradient along the TE legs was almost linear showing a lower value for the $p$-type legs compared to the $n$-type legs due to a higher thermal conductivity of the $p$-type material above $\mathrm{T}=400 \mathrm{~K}$.

It was shown that coatings of the hot $\mathrm{Al}_{2} \mathrm{O}_{3}$ absorber plate by graphite induced a larger temperature gradient in the TOMs and the maximum output power and the conversion efficiency were significantly improved. A heat flux between $4-8 \mathrm{~W} \mathrm{~cm}^{-2}$ resulted in the highest conversion efficiency. The maximum conversion efficiency of $0.082 \%$ was obtained for a TOM with $10 \mathrm{~mm}$ leg length. With a slightly modified geometry of the TOM the conversion efficiency would be $\sim 0.4 \%$ [25]. It was found that the contact resistances which vary in the range of $0.29 \Omega<R_{\text {cont }}<0.64 \Omega$ are limiting the conversion efficiency significantly. Thus, besides the necessity of the development of better thermoelectric materials and the lowering of re-radiation losses, a major part in the improvement of solar thermoelectric converters applied at high temperatures with concentrated solar radiation will be to reduce substantially the contact resistances.

\section{Acknowledgements}

We acknowledge the Swiss Federal Office of Energy and Swiss National Foundation for financial support. We would also like to thank A. Hämmerli and P. Hinz for technical support and A. Shkabko for contact resistance discussions.

\section{References and Notes}

1. Nayak, P.D.K. Two Days National Seminar on Alternative Energy Sources; In Proceedings of V.P.M.'s Polytechnic: Thane, India, 2005. 
2. Steinfeld, A. Solar thermochemical production of hydrogen-a review. Sol. Energy 2005, 78, 603-615.

3. Steinfeld, A.; Palumbo, R. Solar Thermochemical Process Technology. In Encyclopedia of Physical Science \& Technology; Meyers, A., Ed.; Academic Press: San Diego, CA, USA, 2001; Volume 15, pp. 237-256.

4. Tritt, T.M.; Böttner, H.; Chen, L. Thermoelectrics: Direct solar thermal energy conversion. Mater. Res. Bull. 2008, 33, 366-368.

5. Yang, J.; Caillat, T. Thermoelectric materials for space and automotive power generation. Mater. Res. Bull. 2006, 31, 224-229.

6. Kim, S.S.; Yin, F.; Kagawa, Y. Thermoelectricity for crystallographic anisotropy controlled Bi-Te based alloys and p-n modules. J. Alloys Compd. 2006, 419, 306-311

7. Yamashita, O.; Sugihara, S. High-performance bismuth-telluride compounds with highly stable thermoelectric figure of merit. J. Mater. Sci. 2005, 40, 6439-6444.

8. Reddy, E.S.; Noudem, J.G.; Hebert, S.; Goupil, C. Fabrication and properties of four-leg oxide thermoelectric modules. J. Phys. D: Appl. Phys. 2005, 38, 3751-3755.

9. Shin, W.; Muruyama, N.; Ikeda, K.; Sago, S. Thermoelectric power generation using Li-doped $\mathrm{NiO}$ and (Ba, Sr) $\mathrm{PbO}_{3}$ module. J. Power Sources 2001, 103, 80-85.

10. Funahashi, R.; Mikami, M.; Mihara, T.; Urata, S.; Ando, N. A portable thermoelectric-powergenerating module composed of oxide devices. J. Appl. Phys. 2006, 99, 066117.

11. Funahashi, R.; Matsubara, I.; Ikuta, H.; Takeuchi, T.; Mizutani, U.; Sodeoka, S. Oxide single crystal with high thermoelectric performance in air. Japan. J. Appl. Phys. 2000, 39, 1127-1129.

12. Funahashi, R.; Urata, S.; Mizuno, K.; Kouuchi, T.; Mikami, K. Ca $\mathrm{Ca}_{2.7} \mathrm{Bi}_{0.3} \mathrm{Co}_{4} \mathrm{O}_{9} / \mathrm{La}_{0.9} \mathrm{Bi}_{0.1} \mathrm{NiO}_{3}$ thermoelectric devices with high output power density. Appl. Phys. Lett. 2004, 85, 1036-1038.

13. Terasaki, I.; Sasago, Y.; Uchinokura, K. Large thermoelectric power in $\mathrm{NaCo}_{2} \mathrm{O}_{4}$ single crystal. Phys. Rev. B 1997, 56, 12685-12687.

14. Ito, M.; Nagira, T.; Furumoto, D.; Katsuyama, S.; Nagai, H. Synthesis of $\mathrm{Na}_{\mathrm{x}} \mathrm{Co}_{2} \mathrm{O}_{4}$ thermoelectric oxides by the polymerized complex method. Scr. Mater. 2003, 48, 403-408.

15. Zhou, S.; Zhao, J.; Chu, S.; Shi, L. Synthesis, characterization and magnetic properties of lightly doped $\mathrm{La}_{2-\mathrm{x}} \mathrm{Sr}_{\mathrm{x}} \mathrm{CuO}_{4}(\mathrm{x}=0.04)$ nanoparticles. Phys. C 2007, 451, 38-43.

16. Bocher, L.; Robert, R.; Aguirre, M.H.; Malo, S.; Hébert, S.; Maignan, A.; Weidenkaff, A. Thermoelectric and magnetic properties of perovskite-type manganate phases synthesised by ultrasonic spray combustion (USC). Solid State Sci. 2008, 10, 496-501.

17. Weidenkaff, A. Preparation and application of nanostructured perovskite phases. Adv. Eng. Mater. 2004, 6, 709-714.

18. Aguirre, M.H.; Canulescu, S.; Robert, R.; Homazava, N.; Logvinovich, D.; Bocher, L.; Lippert, T.; Döbeli, M.; Weidenkaff, A. Structure, microstructure, and high-temperature transport properties of $\mathrm{La}_{1-\mathrm{x}} \mathrm{Ca}_{\mathrm{x}} \mathrm{MnO}_{3-\delta}$ thin films and polycrystalline bulk materials. J. Appl. Phys. 2008, 103, 013703.

19. Tomeš, P.; Robert, R.; Trottmann, M.; Bocher, L.; Aguirre, M.H.; Hejtmánek, J.; Weidenkaff, A. Synthesis and characterization of new ceramic thermoelectrics implemented in a thermoelectric oxide module. J. Electron. Mater. 2010, doi:10.1007/s11664-010-1214-4. 
20. Hirsch, D.; Zedtwitz, P.V.; Osinga, T.; Kinamore, J.; Steinfeld, A. A new $75 \mathrm{~kW}$ high-flux solar simulator for high-temperature thermal and thermochemical research. J. Sol. Energy Eng. 2003, 125, 117-120.

21. Bocher, L.; Aguirre, M.H.; Logvinovich, D.; Shkabko, A.; Robert, R.; Trottmann, M.; Weidenkaff, A. $\mathrm{CaMn}_{1-\mathrm{x}} \mathrm{Nb}_{\mathrm{x}} \mathrm{O}_{3}(\mathrm{x} \leq 0.08)$ perovskite-type phases as promising new hightemperature n-type thermoelectric materials. Inorg. Chem. 2008, 47, 8077-8085.

22. Snyder, G.J. Application of the compatibility factor to the design of segmented and cascaded thermoelectric generators. Appl. Phys. Lett. 2004, 84, 2436-2438.

23. Bramson, M.A. Infrared Radiation-A Handbook of Applications; Plenum Press: New York, NY, USA, 1968.

24. Rowe, D.M.; Min, G. Evaluation of thermoelectric modules for power generation. J. Power Sources 1998, 73, 193-198.

25. Suter, C.; Tomeš, P.; Steinfeld, A.; Weidenkaff, A. Heat transfer and geometrical analysis of thermoelectric converters driven by concentrated solar radiation. Materials 2010, 3, 2735-2752.

26. Lemonnier, S; Goupil, Ch.; Noudem, J.; Guilmeau, E. Four-leg $\mathrm{Ca}_{0.95} \mathrm{Sm}_{0.05} \mathrm{MnO}_{3}$ unileg thermoelectric device. J. Appl. Phys. 2008, 104, 014505.

(C) 2010 by the authors; licensee Molecular Diversity Preservation International, Basel, Switzerland. This article is an open-access article distributed under the terms and conditions of the Creative Commons Attribution license (http://creativecommons.org/licenses/by/3.0/). 